\title{
Analysis of Annual Maximum Rainfall for Frequency Distribution to Determine the Best-fitted Probability Distribution for Different Sites in Pakistan.
}

Tasir khan ( $\square$ tasirkhan.state@gmail.com )

Lanzhou University https://orcid.org/0000-0003-0651-0418

\section{Yejuan Wang}

Lanzhou University

Mohammad Anwar

International Islamic University

\section{Research Article}

Keywords: Probability Distribution Function, Return Period, PWRMSE, Annual Maximum Hourly Rainfall

Posted Date: August 17th, 2021

DOI: https://doi.org/10.21203/rs.3.rs-780243/v1

License: (1) This work is licensed under a Creative Commons Attribution 4.0 International License.

Read Full License 
Analysis of annual maximum rainfall for frequency distribution to determine the bestfitted probability distribution for different sites in Pakistan.

Tasir Khan ${ }^{1},{ }^{*}$, kalimullah, ${ }^{2}$ Yejuan Wang ${ }^{1,}$ Muhammad salam ${ }^{3}$, Fakhri alam ${ }^{4}$ Mohammad Anwar ${ }^{2}$

1School of Mathematics and Statistics, Gansu Key Laboratory of Applied Mathematics and Complex Systems, Lanzhou University, Lanzhou 730000, China

2. Department of mathematics and statistics, International Islamic University, Islamabad.

3. School of environment and ecology Chongqing University, Chongqing 400045, P.R

4. School of Environmental and Energy Engineering, Beijing University of Technology

*Corresponding author Email:

Dr. Tasir khan

School of Mathematics and Statistics

Lanzhou University, Lanzhou 730000, China

tasirkhan.state@gmail.com 


\title{
Analysis of annual maximum rainfall for frequency distribution to determine the best-fitted probability distribution for different sites in Pakistan
}

\begin{abstract}
In the project of irrigation and addition structure of hydraulic, it is important to assess the specific probability of extreme rainfall. The novelty of this study is the use of KS, Chi-square, root mean square error (RMSE), and peak weight root means square error (PWRMSE) to evaluate the fit theoretical and Empirical distributions. Thirty-seven years of meteorological data from 1980 to 2017, the frequency analysis of the annual maximum rainfall in 10 regions of Pakistan was conducted. Used eight formulas to predict the annual return period of the maximum hourly precipitation every year. Five different probability distribution functions (PDF) are used to predict the probability distribution of the annual maximum hourly rainfall. Use the chi-square test and Kolmogorov- Smirnov to assess the goodness of fit. It shows that the log-logistics distribution is the overall best-fitting PDF of the annual maximum hourly rainfall in most areas of Pakistan. Besides, the peak weight relative mean square error and root mean square error goodness of fit test indicators both indicate that most suitable distribution of the probability function of all stations analysis is similar. The value of root means square error (RMSE) is almost always smaller than peak weight root means square error (PWRMSE). This is due to the higher weighting of value above the average value in the PWRMSE goodness of fit index, while for the RMSE goodness of fit index individual value has an equal weight.
\end{abstract}

Keyword

Probability Distribution Function; Return Period; PWRMSE; Annual Maximum Hourly Rainfall

\section{Introduction}

In hydrology, it includes the option of an acceptable PDF to analyze extreme precipitation events in different areas. Theoretical PDF uncertainty is consistent with real hourly, annual, daily rainfall observations used to estimate the potential likelihood of severe rainfall events (Khudri and Sadia 
2013). However, extreme rainfall and flooding will disrupt many individuals and cause the loss of millions of dollars. Therefore, the risk of such an occurrence is needed for flood control programs, bridges, reservoirs, and other survey management and design staff. The study of hydrology also needs to address the impact of pollutants, extraordinary low flows, and loads on water. Therefore, they influence water sources and their quality (Yuan, Emura et al. 2018). It is critical to assess the statistics of extreme precipitation events because the frequency of extreme events has an impact on flood control measures, as well as their design and operation (Liu, Doan et al. 2015). The fitted distribution has been used to calculate the size of the event which also correlates to a return time that has been greater or less than the documented event's return time. Precise severe precipitation forecasts can help to mitigate storm damage and contribute to more productive damage.

The rainfall season and space, therefore, have an impact on agricultural activities. To a large extent, farmers rely on favorable weather conditions. However, agricultural activity came about as a result of rain. It plays a vital role in determining agricultural output (Audu 2012, Bhandari 2013). (Olofintoye, Sule et al. 2009) stated that, while precipitation varies with time and has uncertain properties, it is possible to predict the amount of rainfall very precisely for different durations using a specific probability distribution. Consequently, the estimation of heavy rainfall is completed during recent engineering training centered on statistical frequency analysis of the maximum rainfall records where the existing sample data can be used to calculate the sample distribution parameters. (Salami 2004, Heo, Ahn et al. 2019) to predict the annual flow profile, clearly recognize a probability distribution model and flow across the Asa River. The results have shown that maximum and minimum fluid flow rates were used with the Gumbel and LP3 distributions. Unfortunately, rainfall information is limited in time and space, which does not always allow reliable estimates. A great number of hydrological applications are based on knowledge of extreme rainfall. (Salami 2004, Yue and Hashino 2007, Chen, Norris et al. 2019). Random variables could be estimated by the probability distribution based on a sufficiently long observation sequence of the maximum annual rainfall. In hydrological research, maximum precipitation is usually determined utilizing lognormal distribution, normal distribution, Pearson type 3, exponential function, generalized distribution of extreme value (GEV), Gumbel distribution, Pareto and Weibull distributions (Amin, Rizwan et al. 2016, Boudrissa, Cheraitia et al. 2017, Douka, Karacostas et al. 2017, Sun, Wang et al. 2017, Machekposhti and Sedghi 2019). 
(Yue and Hashino 2007) Chi-square statistics have been used in Japan to analyze the probability distribution for the fit of the selected samples to the probability distribution. They have decided that the 3 parameters can better be estimated for annual precipitation Lognormal distribution Pearson type 3 (P3). The field of hydrological extreme frequency analysis was rarely used for model selection criteria (Laio, Di Baldassarre et al. 2009). The only way is Schwartz (BIC) or Akaike (AIC) information standards (Sun and Lall 2015). Through furthermore, additional statistical tests can be used to assess the performance of the theoretical distribution, such as Anderson-Darling, which associated the whole range, but the upper tail adds weight. (Delignette-Muller and Dutang 2015, Młyński, Wałęga et al. 2019). In the return period the value increases, the information on the estimation of the result must increase the long rainfall data sequence, and not for short periods. It often exists. In this case, frequency analysis is a good option to maximize the amount of improved quantitative estimates and available data (Hajani and Rahman 2018, García-Marín, Morbidelli et al. 2019).

This study aims to investigate the monthly rainfall distribution characteristics including 10 Pakistani sites that have different PDF distributions, including LN, LL, IG, GG, and IP3 to determine the best-suited probability distribution based on the goodness of fit (GOF), chi-square, KS test, peak weight root mean square error (PWRMSE) and root mean square error (RMSE) in terms of monthly precipitation from 1981-2017.

\section{Area of the study}

There are many specific and regular changes to the climate in Pakistan. Temperature, rainfall, humidity, wind speed, and altitude are the most important variables that affect the weather. Some areas are deserts and are still very warm and dry. The data were used to measure the probable precipitation trend for thirty-seven years. The meteorological department of Islamabad in Pakistan selected ten stations in major cities. The following sites are located in Sindh, Punjab, and Khyber Pakhtunkhwa: Sialkot, Peshawar, Multan, Lahore, Faisalabad, DI Khan, Haiden Abad, Dal Badin, Nawab Shah, and Karachi. The annual maximum rainfall data were collected and used in this study from the Pakistan Metrological Division (PMD) Islamabad. In several decadal periods, the longterm data precipitation between 1981 and 2017 has been analyzed.

This paper examines the maximum rainfall characteristics of each of the following 10 locations. The location of annual maximum rainfall is given in Fig 1. 
Fig.1. map and location of ten selected station in Pakistan

Table.1 lists descriptive statistics for each site, including mean, skewness, kurtosis, latitude, longitude, and altitude. The rainfall series has a record length of 37 years. The latitude of the station is $24^{\circ} 54^{\prime}-34^{\circ} 0^{\prime}$ north latitude and $67^{\circ} 4^{\prime}$ to $74^{\circ} 31^{\prime}$ east longitude. Altitude is an important factor in explaining extreme rainfall. The altitude ranged from $4 \mathrm{~m}$ to $359 \mathrm{~m}$ in this study. The Peshawar station (359m high) has the highest altitude of all stations, while the Sialkot and Lahore stations (256m, 215m high) are close in height to the Peshawar station. However, the Karachi station (4 m high) has the lowest altitude in the GIS figure 1.

Table 1. Descriptive statistics and geographical location of ten stations in Pakistan

\section{Methodology.}

\subsection{Return period (T) analysis}

The $(\mathrm{T})$ is an estimated probability of exceeding procedures (e.g. severe precipitation or flood over a longer duration) and indicates the possibility of exceeding the return period (irregularly known as repeat interval) (Mays, 2005). $\mathrm{T}$ is the amount of the possible time between a major or equal occurrence and the occurrence of a particular event. If a variable (X) of rainfall is greater than $\mathrm{x}$ once in $\mathrm{T}$ year, then the likelihood of existence.

The following formula shows the $\mathrm{P}(\mathrm{X} \geq \mathrm{x})$ of such a variable.

$p=\frac{1}{T}(X \geq x)$ or $\quad T=\frac{1}{P}(X \geq x)$

\subsection{Plotting position}

The plot position represents the likelihood value assigned to each data point to be drawn. Many approaches, most of the empirical, were designed to determine the plot position. The following equations express the majority of the plot position formulas (Te Chow 2010).

$P=\frac{1}{T}=(b-c) /(n+1-2 c)$ 
where $b$ is the rank of the values sorted in descending order in the list, the total number $n$ of the value to be drawn, $\mathrm{c}$ is the parameter, which is dissimilar and different formulas ( for Hazen $\mathrm{c}=$ 0.5 , Weibull $\mathrm{c}=0$, chegodayev, $\mathrm{c}=0.3$, for Blom $\mathrm{c}=0.375$, for Tukey $\mathrm{c}=0.333$ and Grigoten $\mathrm{c}=$ 0.44) (Chow 1964).

Table 2. Plotting positions and different formulas for return period (T)

\subsection{Probability distribution function (PDF) analysis}

Through, large probability information is summarized in a sample and is related to parameters using a suitable distribution of hydrological observations. The purpose of this study is to determine the best distribution of annual rainfall in Pakistan. For hydrological analytics, we have utilized and linked several PDFs, including GG, IG, log log-logistic, LN3, and LP3 (Fawad, Ahmad et al. 2018). A comprehensive description of this PDF and cumulative distribution function CDF shows in the following table.

Table 3. Description of PDF and CDF of five different distribution

Another method can be used to achieve a maximum probability estimate for the distribution parameters value such as linear moments in this study using $\mathrm{L}$ moments. If the hypothesis is unbiased and optimum with a minimal variances parameter estimate, the characteristics of the $\mathrm{L}$ moment method will be asymptotic (Strupczewski, Singh et al. 2002)

If we have many high-quality data and a good model, we estimate our default parameters. While guidelines exist on how parameter uncertainty can be identified. In the probabilistic sensitivity analysis, this should be taken into account. Uncertainty estimates of distribution parameters in the statistical model to express random uncertainty (Degeling, IJzerman et al. 2017). The theoretical distribution and the KS, RMSE, chi-square test are therefore used according to the Empirical Distribution. If the theoretical distribution for every analysis shows consistency, followed by the best fit of the distribution, measures are taken.

\subsection{The goodness of fit tests}

A variety of factors influence the special probability distributions, including the PD parameters evaluation methods, comparison methods, and the availability of rainfall data. The Chi-square and 
KS tests were used to determine the fitness of some PDs in this study. The KS and chi-square test were used to measure test statistics that define that described the theoretical and actual value estimates from distributions. Furthermore, to verify the visual calculations of the goodness of fit. The above test plot and fit test applied to the maximum rainfall data has a number of advantages (Morgan, Lackner et al. 2009, Lollchund, Boojhawon et al. 2014, Cassalho, Beskow et al. 2018, Fawad, Yan et al. 2019). The above-mentioned weather test statistics and fitted tests can be used to reliably pick the best-fit distributions.

The Chi-square test ( $\chi 2)$ (Kumar and Bhardwaj 2015) compares the number of observations made in different class intervals (expected values are determined based on the division under discussion). The chi-square test will be calculated using the equation below.

The $\chi 2$ test statistic is given by

$\chi^{2}=\sum_{i=1}^{r} \frac{\left(O_{i}-N p_{i}\right)^{2}}{E_{i}}=\sum_{i=1}^{r} \frac{\left(O_{i}-E_{i}\right)^{2}}{E_{i}}$

$E_{i}=F\left(x_{i+1}\right)-F\left(x_{i}\right)$

$k=1+\log _{2} n$

The number of observations $(1,2,3 \ldots \mathrm{k})$ and the total number $(\mathrm{F})$ represent the predicted annual maximum hourly rainfall based on various distributions. The CDF is the nth percentile of the probability distribution discovered by of the $\beta 2$ test.

A KS test based on empirical distribution functions that determines whether a sample is from a hypothetical continuous distribution. Suppose a random sample $x_{1}, x_{2}, x_{3}, \ldots, x_{n}$ from a distribution, which EDF is given as

$F_{n}(x)=\frac{1}{n}[$ number of observation $\leq x]$

The Kolmogorov Simonov test depends on the maximum vertical distance between the EDF and the theoretical PD. The test statistics as;

$D=\max _{1 \leq i \leq n},\left[F\left(x_{i}\right)-\frac{i-1}{n}, \frac{i}{n}-F\left(x_{i}\right)\right]$

In equation (4), $F\left(x_{i}\right)$ is the cumulative distribution function $x_{i}$ is the $i^{\text {th }}$ order and sample size $\mathrm{n}$.

The most appropriate function for random variables in the empirical model is to identify them based on the indicators used in evaluation, such as the hydrological models peak weight root mean 
square error (PWRMSE) and root mean square error (RMSE). The following relationship describe the goodness of the fitting index under consideration.

$$
\begin{gathered}
R M S E=\sqrt{\frac{\sum_{i=1}^{n}\left(O_{i}-\hat{O}_{i}\right)^{2}}{n}} \\
P W R M S E=\sqrt{\frac{\sum_{i=1}^{n}\left(O_{i}-P_{i}\right)^{2} \frac{O_{i}+\bar{O}}{2 \bar{O}}}{n}}
\end{gathered}
$$

Where

$\mathrm{n}$ - Sample size;

$\mathrm{Oi}$ - for a year I actual observed values

$\mathrm{Pi}$ - for a year I predicted values

$\bar{O}$ - An average of actual values;

$\hat{O}-$ is the estimated value of actual value

$\mathrm{P}$ - an average of predicted values.

\section{Results and discussion}

\subsection{Return period $(\mathrm{T})$}

To compute the returning period for extreme rainfall at selected location using various formulas. Figure 2 shows the exposed results by using Excel State and ALEA application. The equation 3-2 formula, which is used to predict the annual rotation period for all sites with rainfall rank b ranging from 1 to 37, will obviously yield a similar result. Rainfall has different values on the y-axis than on the X-. According to the formula used, Dalbandin, Haider Abad, Karachi and Sialkot are likely to have the highest extreme measure is statistics 40-50 millimeter per hour each 37-60 years' is predictable for Nawab Shah, Peshawar, Faisalabad and DI khan, Lahore is likely to receive 110 millimeters per hour every 37-80 years, while Sialkot is likely to receive 150 millimeters per hour every 37-80 years. The return period(T) investigation reveals that $(b=1)$ for the highest ranked, the difference between the various formulas is up to 37 years and for another case of $b=2$ or less, the difference is 3.3 in the lowest ranks. The Hazen procedure can be employed for the highest ranked period assessment, in accordance with all the methods. Everything is done with the formula 
of Cunnae, Gringorten, Tukey, Blom, Chegodavev, California and Weibull. These are the best approach to hydraulic design for forecasting the return period for the extreme event.

Figure 2. Return period in years computed using eight different formulas for ten locations in of Pakistan

\subsection{Probability distribution function (PDF)}

To calculate the maximum annual precipitation in the probability distribution analysis for the selected area by using several PDF. Figure 3 shows the average annual rainfall in different areas (Dalbadin, Haider Abad, Nawab Shah, Karachi, Peshawar, Sialkot, DI Khan, and Multan) of different locations. The results show a different distributions of probabilities for each position. The yearly rainfall is relatively high for Sialkot, Peshawar, and DI Khan, and Karachi regions compared with other regions. One PDF for every workstation is the best choice of these PDFs. The analysis of best fit has been completed in the next chapter.

Figure 3. Probability distribution analysis of annual maximum hourly rainfall for representative locations of the different regions using various.

\subsection{Determination of the best fit}

The overall distribution of the population should be estimated by general knowledge. The typical way in which the basic distribution is evaluated by changing the observed distribution to a theoretical distribution as mentioned above. The frequencies observed in the data are comparable to predetermined theoretical distribution frequency since some variable types are precisely distributed (Tilahun 2006).

The results in Table 4 show six locations in the selected locations, each with its two LP3 sites and $\log$ Log-normal, best suited for Sialkot, Multan, Lahore and Karachi. The best choice is for the LN and LP3 distribution (LN only slightly below that distribution LL). The second best distribution is approximately uniform in all other cases LN, LP3, GG, and IGU. We can thus conclude that the LL distribution is possible to predict maximum annual precipitation, be most appropriate for PDF in most observatories in Pakistan.

Table 4. Values of the analyzed goodness-of-fit measures matching the distributions. In 10 locations with the best fit.

The CDF is $\mathrm{n}$ of the estimated likelihood distribution, where $\mathrm{n}$ is the sample size. The KS test for the best PDF for selected site was used in this analysis. The best PDF was measured and found for 
the chosen main position and results shown in the Table 4. The results show that the LL distribution in six sites is more convenient, GG is best suited for three sites and only one site is different. The most convenient option is GG (only slightly above LL distributors). In all other cases, the distribution between GG and LP3 is approximately the second best-fit. We can thus deduce that most observatories are able to calculate rainfall by using the LL distribution.

Table 4 indicates that each value that PWRMSE determines log-logistic distribution is the best PDF for the value appraisal. Other best appropriate distributions, according to goodness of fit test, are LP3, GG, and LN. The root means square error (RMSE) GOF index produced the same types of results. Furthermore, the relative peak weight also shows that the probability distribution function of all stations analysis is similar, with the roots and square error goodness of fitting test indicator. The RMSE value is nearly always lower than that of PWRMSE. This is because the of the PWRMSE fit index is higher than the average value, while the RMSE value of the fit index is equal in weight. However, the distribution performance of two parameters has been observed in the analysis of distribution function of Gamma and LN2 (Rahman, Rahman et al. 2013). Therefore, the number of adjusted GLO distribution of EV1 series, which was considered to be the most suited PDF for only one sequence, originated in that maximum rainfall series (Beskow, Caldeira et al. 2015). Although the Rio Grande presentation was not satisfactory, several authors have reported acceptable performance of GLO distributions in regional research (Beskow, Caldeira et al. 2015), as GEV made adequate adaptation to more than $96 \%$ of the series. In this study, GEV offers better modifications for shorter sequences and better modifications for longer average sequences when compared to other PDFs. However, those areas in which hydrological observations often lack a wide historic sequence, this feature is very important ( $\mathrm{Ng}$, Yap et al. 2020). A suitable probability distribution was chosen to investigate the annual maximum precipitation in hot regions of peninsular Malaysia. The River Basin maximum annual rainfall is described by the Gumbel, 
Gamma, Log Pearson type 3, and GEV distribution. Evaluate the performance of GOF test and find out, the GEV distribution is the best fitting distribution to distinguish the sequence of precipitation, because of its high flexibility and efficiency.

Maximum annual rainfall indicate that there is a subpopulation in the observations, indicating that the weather mechanism that activates strong rainfall has changed, such as high water vapor content, temperature variation between continuous and incoming air, duration of low pressure in a given area and thermodynamic balance of atmospheric condition in local areas (Młyński, Petroselli et al. 2018). Another study (Villarini 2012) has suggested that log Gamma and Weibull are the most appropriate distribution in central Poland. Therefore, (Wdowikowski, Kaźmierczak et al. 2016) demonstrated that the generalized Pareto and exponential distribution are the best method for estimating P max p\% in the Odra Basin. Although, (Alam, Emura et al. 2018) considers that the GEV function to be the best distribution for estimating the highest annual average precipitation. In central European countries, there is a high risk of excess due to the high mid-tall. Regardless of such studies, it should be noted that the shape of the probability distribution, particularly its parameters is closely related to the area metrological, geographic and physical characteristics that influence precipitation, where the maximum rainfall has a precise probability in determining if its excess.

\section{Conclusion}

In this study, we concluded that frequency analysis of the annual hourly maximum rainfall of ten stations in Pakistan, employing eight different methods to predict the return time and eight PDFs for probability distribution modeling, based on the weather conditions 37 years' data of Pakistan from 1981 to 2017. The PDF analysis was also conducted by means of the chi-square test on an annual hourly maximum rainfall in selected areas of Pakistan.

Through, returning period analysis was used to determine the length of the data period for the highest-ranked rainfall event based on the different range of the return period expected by the eight 
different formulas. This difference becomes smaller and smaller as the level decrease. Among these formulas, the Hazen formula estimates the highest returning period, while the California formula estimates the lowest return period.

We investigate whether the goodness of fit peak-weight-mean-square-error (PWRMSE) index, which is commonly used to assess the quality of precipitation model, can be used to identify the best fitting statistical distribution. The goodness of fit index based on root-mean-square- error (RMSE) confirms that LL, LP3 is the best-fitted distribution. Furthermore, it is decided that PWRMSE rather than other goodness of fit indicator, can be used as a goodness of fit indicator.

By the KS test we find out the fit distribution, we see that LL is the most suitable distribution for many sites and GG is fit for three sites and LP3 for one site. So, GG and LP3 are the second-best fitting distribution

Through, the best-fitting analysis of PDF reveals that, with the exception of four locations (Sialkot, Multan, Lahore, and Karachi), the LL distribution is most suitable for ten selected locations. In this case, the LP3 distribution only slightly better distribution than LL. While, in all remaining cases, the second-best fitting distribution is equally divided between LN and LP3. Therefore, the LL distribution may be the most suitable PDF, and the chi-square test can predict the probability of the annual maximum hourly rainfall at most observation locations in Pakistan. It will help in the prediction of maximum hourly rainfall, drainage engineering, and drainage structure of Pakistan in the future.

\section{Acknowledgments}

We thank our respected reviewers and especially Yejuan Wang for their valuable comments and suggestions that helped us to improve this paper.

\section{Author's contribution}

All authors contributed to the study's conception and design. Material preparation, data collection, and analysis were performed by [Tasir khan], [kalimullah], [Muhammad Salam], [Fakhri Alam], and [Yejuan Wang]. The first draft of the manuscript was written by [full name] and all authors commented on previous versions of the manuscript. All authors read and approved the final manuscript. 
- Conceptualization: [yejuan wang],; Methodology: [kalimullah], Formal analysis and investigation: [Tasir khan]. Writing - original draft preparation: [kalimullah]; Writing - review and editing: [Muhammad salam, Fakhri alam]. Supervision: [yejuan wang].

\section{Conflict of interest}

The authors declare that they have no conflict of interest

\section{Funding. No}

\section{Author's contribution}

All authors contributed to the study conception and design. Material preparation, data collection and analysis were performed by [Tasir khan] and [yejuan wang]. The first draft of the manuscript was written by [Tasir khan] and all authors commented on previous versions of the manuscript. All authors read and approved the final manuscript.Tasir Khan. Data curation, Writing- Original draft preparation. Yejuang wang; Supervision:

\section{Data availability statement}

All the authors of this manuscript confirmed that the data supporting the findings of this study are available in the article. All the required data is available and easily accessible.

\section{https://www.rstudio.com/products/rstudio/download/}

\section{https://easyfit.en.softonic.com/}

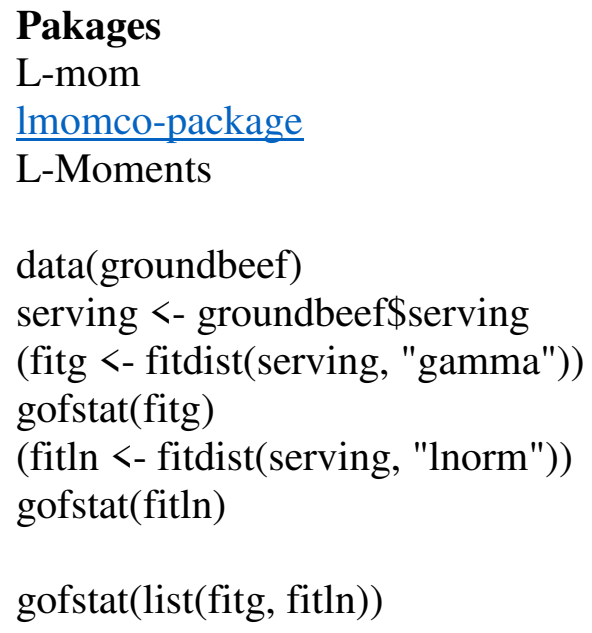




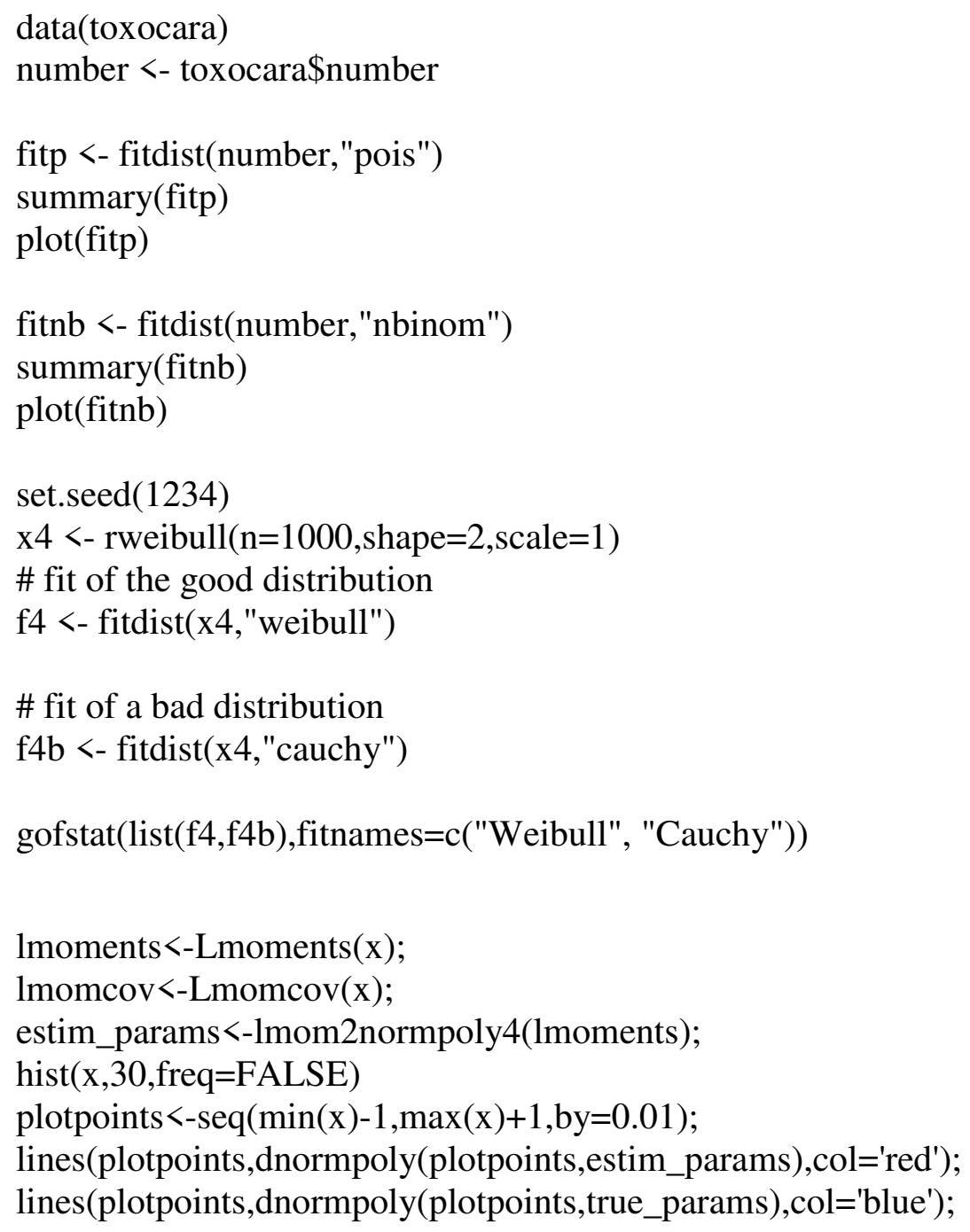

\section{Consent for publication}

All the authors agree to publish this paper

\section{Ethical statement}

All experimental procedure were approved by the animal welfare and ethics committee of Lanzhou University (LZU-201805-224)

\section{Consent to participate}

This study involve no living organisms or their products so don't need any consent of participate 


\section{References}

Alam, M. A., et al. (2018). "Best-fit probability distributions and return periods for maximum monthly rainfall in Bangladesh." Climate 6(1): 9.

Amin, M., et al. (2016). "A best-fit probability distribution for the estimation of rainfall in northern regions of Pakistan." Open Life Sciences 11(1): 432-440.

Audu, E. (2012). "A descriptive analysis of rainfall for agricultural planning in Lokoja local government area of Kogi state, Nigeria." International Journal of Science and Technology 2(12): 850-855.

Beskow, S., et al. (2015). "Multiparameter probability distributions for heavy rainfall modeling in extreme southern Brazil." Journal of Hydrology: Regional Studies 4: 123-133.

Bhandari, G. (2013). "Effect of precipitation and temperature variation on the yield of major cereals in Dadeldhura district of Far Western development region, Nepal." International journal of plant, animal and environmental sciences 3(1): 247-256.

Boudrissa, N., et al. (2017). "Modelling maximum daily yearly rainfall in northern Algeria using generalized extreme value distributions from 1936 to 2009." Meteorological Applications 24(1): 114-119.

Cassalho, F., et al. (2018). "At-site flood frequency analysis coupled with multiparameter probability distributions." Water Resources Management 32(1): 285-300.

Chen, G., et al. (2019). "Thermodynamic and dynamic mechanisms for hydrological cycle intensification over the full probability distribution of precipitation events." Journal of the Atmospheric Sciences 76(2): 497-516.

Chow, V. T. (1964). "Handbook of applied hydrology."

Degeling, K., et al. (2017). "Accounting for parameter uncertainty in the definition of parametric distributions used to describe individual patient variation in health economic models." BMC medical research methodology 17(1): 1-12.

Delignette-Muller, M. L. and C. Dutang (2015). "fitdistrplus: An R package for fitting distributions." Journal of statistical software 64(4): 1-34.

Douka, M., et al. (2017). Annual and seasonal extreme precipitation probability distributions at Thessaloniki based upon hourly values. Perspectives on Atmospheric Sciences, Springer: 521-527. 
Fawad, M., et al. (2018). "Estimation of wind speed using regional frequency analysis based on linearmoments." International Journal of Climatology 38(12): 4431-4444.

Fawad, M., et al. (2019). "Multiparameter probability distributions for at-site frequency analysis of annual maximum wind speed with L-Moments for parameter estimation." Energy 181: 724-737.

García-Marín, A. P., et al. (2019). "On the choice of the optimal frequency analysis of annual extreme rainfall by multifractal approach." Journal of hydrology 575: 1267-1279.

Hajani, E. and A. Rahman (2018). "Design rainfall estimation: comparison between GEV and LP3 distributions and at-site and regional estimates." Natural Hazards 93(1): 67-88.

Heo, J.-H., et al. (2019). "Probability distributions for a quantile mapping technique for a bias correction of precipitation data: A case study to precipitation data under climate change." Water 11(7): 1475.

Khudri, M. M. and F. Sadia (2013). "Determination of the best fit probability distribution for annual extreme precipitation in Bangladesh." European Journal of Scientific Research 103(3): 391-404.

Laio, F., et al. (2009). "Model selection techniques for the frequency analysis of hydrological extremes." Water Resources Research 45(7).

Liu, J., et al. (2015). "Regional frequency analysis of extreme rainfall events in Jakarta." Natural Hazards 75(2): 1075-1104.

Lollchund, R. M., et al. (2014). "Statistical modelling of wind speed data for Mauritius." International Journal of Renewable Energy Research (IJRER) 4(4): 1056-1064.

Machekposhti, K. H. and H. Sedghi (2019). "Determination of the Best Fit Probability Distribution for Annual Rainfall in Karkheh River at Iran." International Journal of Environmental and Ecological Engineering 13(2): 69-75.

Młyński, D., et al. (2018). "Flood frequency analysis by an event-based rainfall-runoff model in selected catchments of southern Poland." Soil and Water Research 13(3): 170-176.

Młyński, D., et al. (2019). "Estimating maximum daily precipitation in the upper Vistula basin, Poland." Atmosphere 10(2): 43.

Morgan, E., et al. (2009). "Probability distributions for offshore wind speeds." AGUFM 2009: A31F-0179. 
$\mathrm{Ng}$, J., et al. (2020). Investigation of the best fit probability distribution for annual maximum rainfall in Kelantan River Basin. IOP Conference Series: Earth and Environmental Science, IOP Publishing.

Olofintoye, O., et al. (2009). "Best-fit Probability distribution model for peak daily rainfall of selected Cities in Nigeria." New York Science Journal 2(3): 1-12.

Rahman, A. S., et al. (2013). "A study on selection of probability distributions for at-site flood frequency analysis in Australia." Natural hazards 69(3): 1803-1813.

Salami, A. (2004). "Prediction of the annual flow regime along Asa River using probability distribution models." AMSE periodical 65: 41-56.

Strupczewski, W. G., et al. (2002). "Asymptotic bias of estimation methods caused by the assumption of false probability distribution." Journal of Hydrology 258(1-4): 122-148.

Sun, H., et al. (2017). "Regional frequency analysis of observed sub-daily rainfall maxima over eastern China." Advances in atmospheric sciences 34(2): 209-225.

Sun, X. and U. Lall (2015). "Spatially coherent trends of annual maximum daily precipitation in the United States." Geophysical Research Letters 42(22): 9781-9789.

Te Chow, V. (2010). Applied hydrology, Tata McGraw-Hill Education.

Villarini, G. (2012). "Analyses of annual and seasonal maximum daily rainfall accumulations for Ukraine, Moldova, and Romania." International Journal of Climatology 32(14): 2213-2226.

Wdowikowski, M., et al. (2016). "Maximum daily rainfall analysis at selected meteorological stations in the upper Lusatian Neisse River basin." Meteorology Hydrology and Water Management. Research and Operational Applications 4.

Yuan, J., et al. (2018). "Frequency analysis of annual maximum hourly precipitation and determination of best fit probability distribution for regions in Japan." Urban climate 24: 276-286.

Yue, S. and M. Hashino (2007). "Probability distribution of annual, seasonal and monthly precipitation in Japan." Hydrological sciences journal 52(5): 863-877. 

Figures

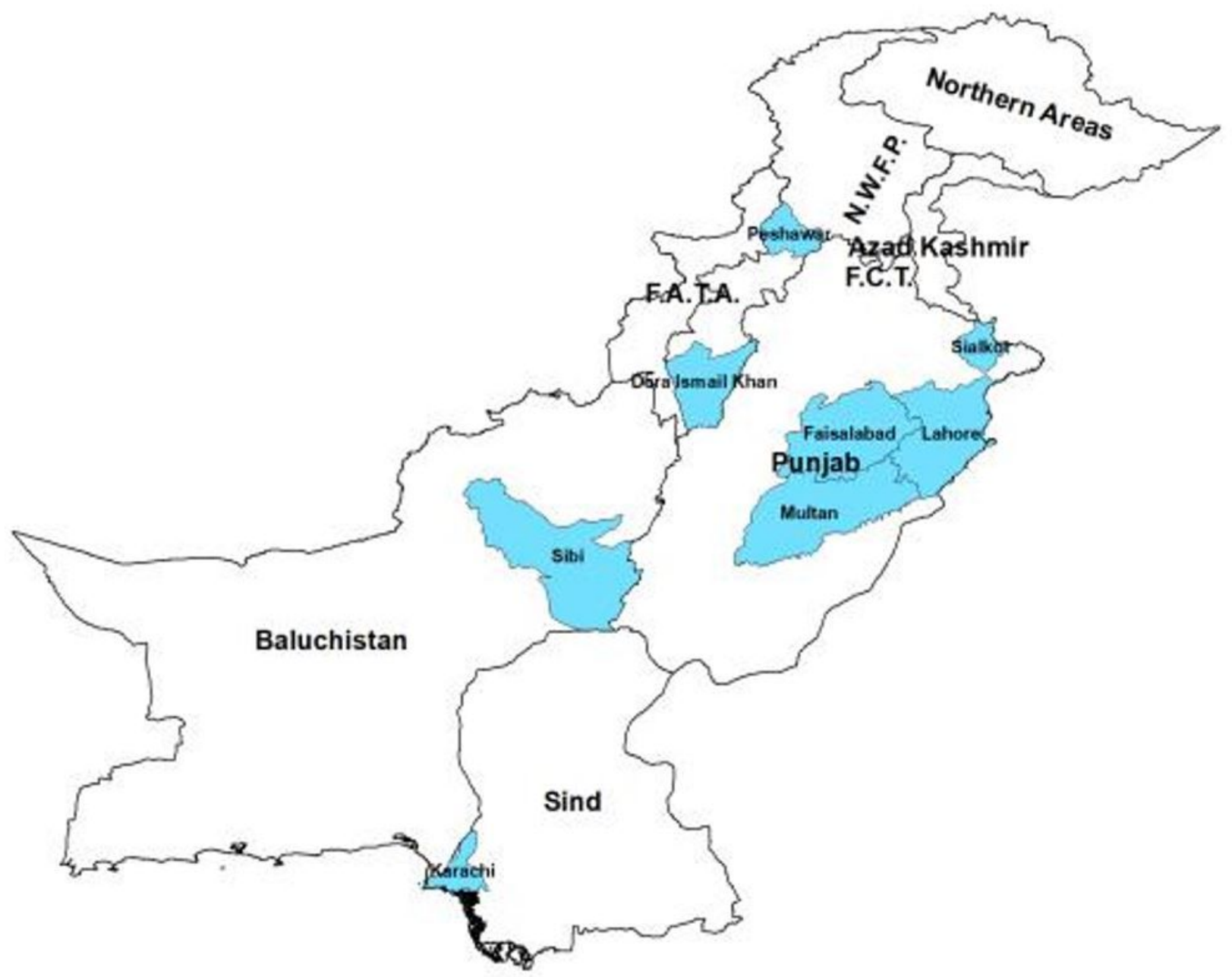

Figure 1

map and location of ten selected station in Pakistan 

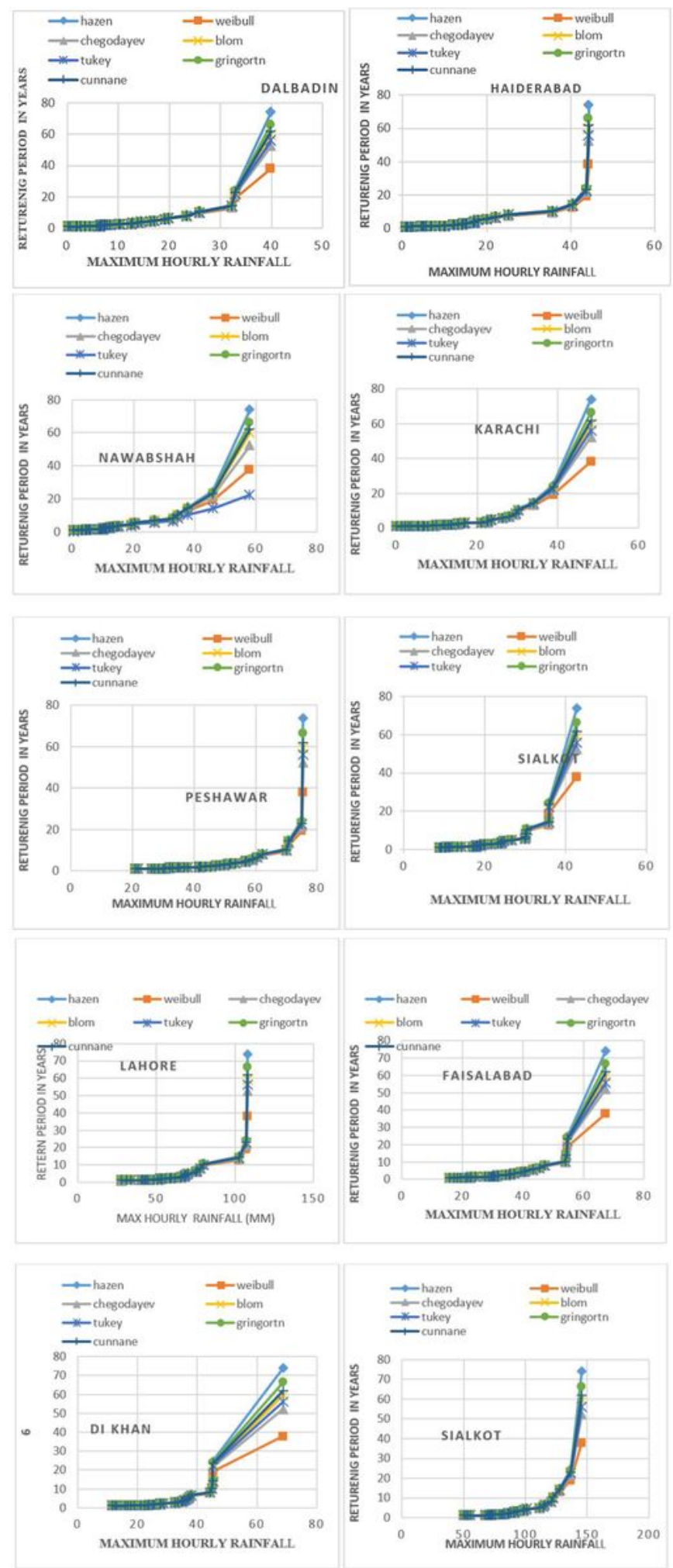

\section{Figure 2}

Return period in years computed using eight different formulas for ten locations in of Pakistan 

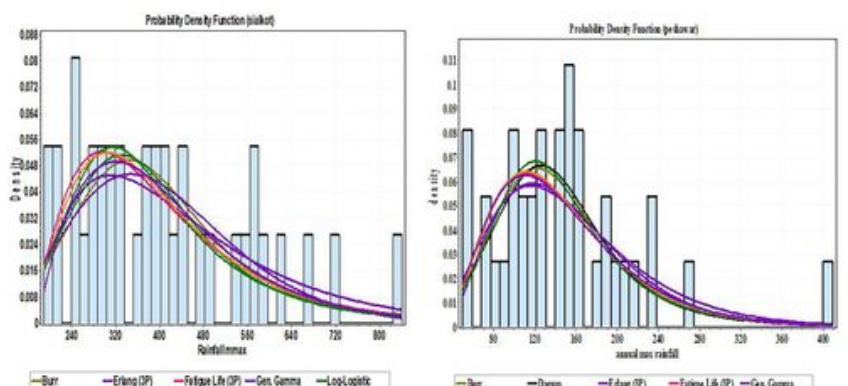

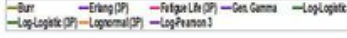
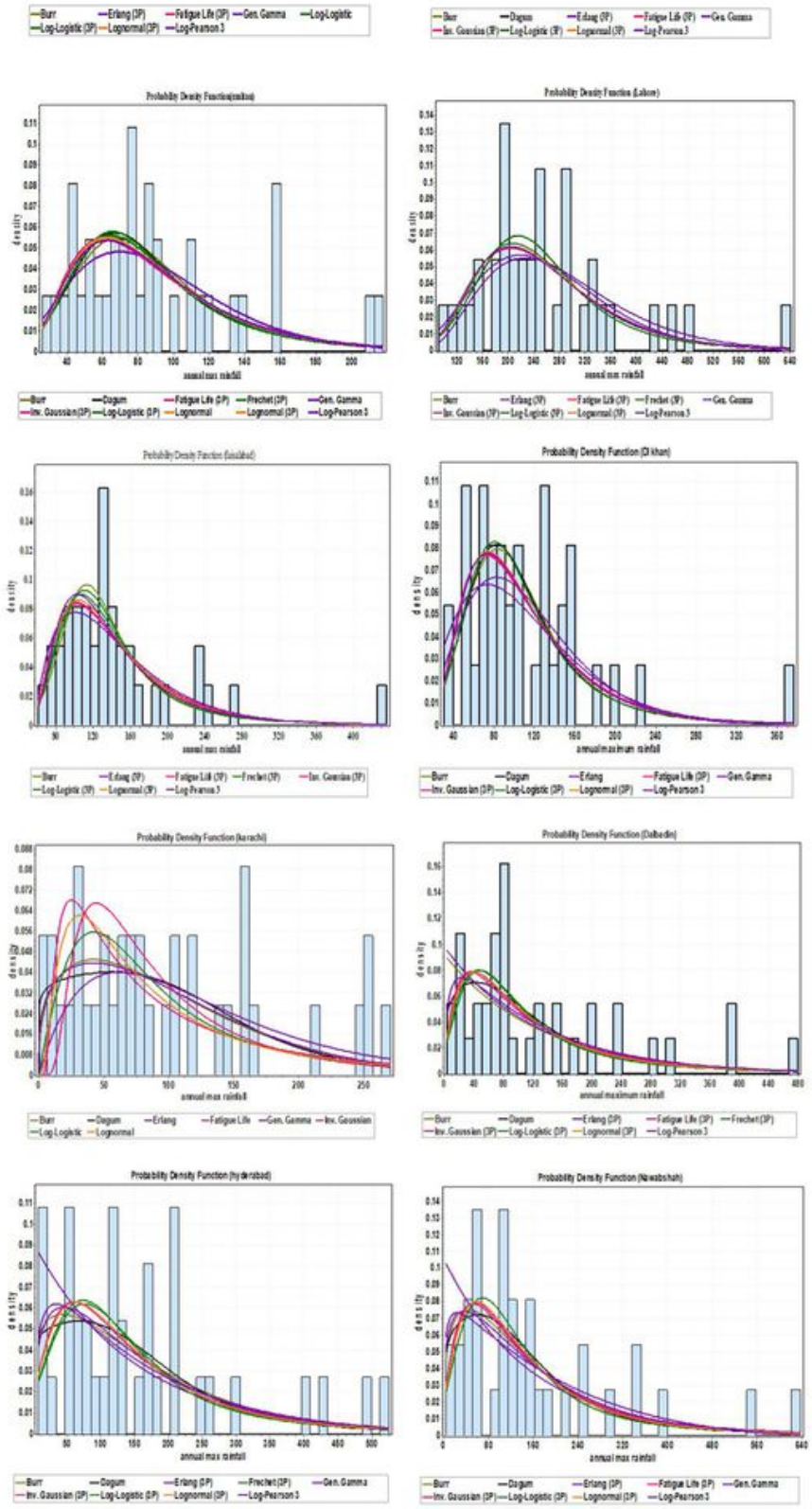

Figure 3

Probability distribution analysis of annual maximum hourly rainfall for representative locations of the different regions using various. 